\title{
Development and cross-validation of prediction equations for estimating resting energy expenditure in severely obese Caucasian children and adolescents
}

\author{
Stefano Lazzer ${ }^{1,2}$, Fiorenza Agosti ${ }^{1}$, Alessandra De $\mathrm{Col}^{1}$ and Alessandro Sartorio ${ }^{1,3 *}$ \\ ${ }^{1}$ Experimental Laboratory for Endocrinological Research, Italian Institute for Auxology, IRCCS, Milan and Piancavallo (VB), Italy \\ ${ }^{2}$ Department of Biomedical Sciences and Technologies, University of Udine, Udine, Italy \\ ${ }^{3}$ Division of Auxology, Italian Institute for Auxology, IRCCS, Milan and Piancavallo (VB), Italy
}

(Received 1 February 2006 - Revised 4 July 2006 - Accepted 17 July 2006)

\begin{abstract}
The objectives of the present study were to develop and cross-validate new equations for predicting resting energy expenditure (REE) in severely obese children and adolescents, and to determine the accuracy of new equations using the Bland-Altman method. The subjects of the study were 574 obese Caucasian children and adolescents (mean BMI $z$-score 3.3). REE was determined by indirect calorimetry and body composition by bioelectrical impedance analysis. Equations were derived by stepwise multiple regression analysis using a calibration cohort of 287 subjects and the equations were cross-validated in the remaining 287 subjects. Two new specific equations based on anthropometric parameters were generated as follows: (1) $\mathrm{REE}=(\operatorname{Sex} \times 892.68)-($ Age $\times 115.93)+($ Weight $\times 54.96)+($ Stature $\times 1816.23)+1484.50\left(R^{2} 0.66\right.$; SE 1028.97 kJ $)$; (2) $\quad \mathrm{REE}=(\operatorname{Sex} \times 909 \cdot 12)-($ Age $\times 107.48)+($ fat-free mass $\times 68.39)+($ fat mass $\times 55 \cdot 19)+3631 \cdot 23\left(R^{2} 0.66\right.$; sE $\left.1034 \cdot 28 \mathrm{~kJ}\right)$. In the crossvalidation group, mean predicted REE values were not significantly different from the mean measured REE for all children and adolescents, as well as for boys and for girls (difference $<2 \%$ ) and the limits of agreement $( \pm 2 \mathrm{SD}$ ) were +2.06 and $-1.77 \mathrm{MJ} / \mathrm{d}$ (NS). The new prediction equations allow an accurate estimation of REE in groups of severely obese children and adolescents. These equations might be useful for health care professionals and researchers when estimating REE in severely obese children and adolescents.
\end{abstract}

Prediction equation: Energy expenditure: Children: Adolescents: Body composition: Obesity

The increasing prevalence of obesity in childhood during the last decades (Lobstein \& Frelut, 2003) is considered to result mainly from a mismatch between energy intake and energy expenditure (Bouchard \& Blair, 1999; Flatt, 2001). In spite of their reduced physical activity and a relatively lower thermic effect of food (Maffeis et al. 1993; Salas-Salvado et al. 1993), obese children and adolescents exhibit a higher daily energy expenditure than non-obese subjects (Ekelund et al. 2002; Lazzer et al. 2003). This apparent paradox is due to both a higher resting energy expenditure (REE) than that of non-obese subjects (Dietz et al. 1994; Molnar \& Schutz, 1997) and similar or higher physical activity energy expenditure because of the higher energy cost of weight-bearing activities (Ekelund et al. 2002; Lazzer et al. 2003). REE corresponds to energy expended for homeostatic processes mainly in organs. It accounts for $60-70 \%$ of daily energy expenditure in sedentary individuals (Lazzer et al. 2004). The higher REE of obese subjects is mostly related to their higher fat-free mass (FFM) and fat mass (FM) (Dietz et al. 1994; Molnar \& Schutz, 1997).
The ability to predict REE accurately in obese subjects is of utmost importance for adequate dietary therapy because it provides the basis to attain a desired level of energy deficit. The gold method for the measurement of REE is indirect calorimetry; however, its complex nature, the lack of skilled staff, and the high cost of equipment limit its regular use at clinical level, both for diagnostic and prognostic purposes. Since the beginning of the 20th century, several authors have tried to address the problem by developing equations for predicting REE in children and adolescents on the basis of anthropometric and body composition parameters (Harris \& Benedict, 1919; Schofield, 1985; World Health Organization, 1985; Tverskaya et al. 1998; Derumeaux-Burel et al. 2004). FFM and FM explain inter-individual variance in REE better than does body weight in obese subjects (Ravussin et al. 1986; DeLany et al. 2002), but body composition is rarely considered in the equation to estimate REE.

Previous studies that tested the accuracy of REE equations in children and adolescents (Dietz et al. 1991) concluded that the World Health Organization (1985) or the Schofield (1985)

Abbreviations: BIA, bioelectrical impedance analysis; FFM, fat-free mass; FM, fat mass; MREE, measured resting energy expenditure; PREE, predicted resting energy expenditure; REE, resting energy expenditure.

* Corresponding author: Dr Alessandro Sartorio, fax +3902 619112435, email sartorio@auxologico.it 
equations were the most accurate. However, because current Western populations show a greater degree of severe childhood obesity than those where the available equations for obese children and adolescents have been developed, there is a need for new equations for this population.

The objectives of the present study were: (1) to develop and cross-validate new equations for predicting REE in severely obese Caucasian children and adolescents; (2) to validate the new equations with a second independent population of obese adolescents; and (3) to determine the accuracy of new equations using the Bland-Altman method (Bland \& Altman, 1986).

\section{Subjects and methods}

\section{Subjects}

The participants in the study were 574 obese Caucasian children and adolescents (242 boys and 332 girls) aged 7-18 years. The subjects were recruited from the Division of Auxology, Italian Institute for Auxology, IRCCS, Piancavallo (VB), Italy. The inclusion criteria were: age between 7 and 18 years, BMI above the 97th percentile for gender and chronological age (Luciano et al. 1997). Subjects who had previously participated in weight management programmes, had overt metabolic and/or endocrine diseases (e.g. diabetes, hypothyroidism, hypertension, amenorrhoea), and those taking medications regularly or using any drugs known to influence energy metabolism were excluded. In particular, at recruitment, $18 \%$ of subjects were excluded for their high blood pressure (NHBP, 2004) and $2 \%$ for their higher glycaemia (American Diabetes Association, 2000).

The experimental protocol was approved by the Ethics Committee of the Italian Institute for Auxology, Milan (Italy). Before the study began, the purpose and objectives were carefully explained to each subject and his or her parents. Written informed consent was obtained from all adolescents and their parents.

Measurements were performed during the stable body weight period before the beginning of the weight-reduction programme. The fasting subjects were taken to the laboratory and the REE, body weight, stature and body composition by bioelectrical impedance analysis (BIA) were determined.

\section{Physical characteristics and body composition}

Body weight was measured to the nearest $0 \cdot 1 \mathrm{~kg}$ with a manual weighing scale (Seca 709; Seca, Hamburg, Germany). Stature was measured to the nearest $0.5 \mathrm{~cm}$ on a standardised wallmounted height board. The standard deviation score for BMI $z$-score was determined by the following formula:

$$
z=\left[(Q / M)^{L}-1\right] /(L \times S)
$$

where $Q$ is the observed BMI; BMI variations (RollandCachera et al. 1991; Luciano et al. 1997) were used to obtain $L$ (power variation with age), $S$ (coefficient of variation) and $M$ (the 50th centile). Pubertal stage was evaluated according to the methods of Tanner (1961) (genitalia and pubic hair).

Body composition was measured using BIA with a tetrapolar impedancemeter (Human-IM Scan; DS-Medigroup, Milan,
Italy). Measurements were performed according to the method of Lukaski (1987) after 20 min rest in a supine position with relaxed arms and legs without any contact with other body parts. FFM and FM were estimated using the prediction equations developed by Lazzer et al. (2005) from BIA, with a group of 143 obese adolescents (BMI $z$-score: 3.2; \%FM: $34 \cdot 5)$ aged $12-17$ years and validated by dual-energy X-ray absorptiometry:

Boys :

$$
\begin{aligned}
\mathrm{FM}= & 0.775 \times \text { Weight }-0.720 \times\left(\text { Stature }^{2} / \text { Resistance }\right) \\
& -0.221 \times \text { Reactance }+17.84 \\
& R^{2} 0.96(\text { SE } 1.66) \mathrm{kg}
\end{aligned}
$$

Girls :

$$
\begin{aligned}
\mathrm{FM}= & 0.705 \times \text { Weight }-0.522 \times\left(\text { Stature }^{2} / \text { Resistance }\right) \\
& -0.133 \times \text { Reactance }+8.83 \\
& R^{2} 0.93(\mathrm{SE} 1.80) \mathrm{kg}
\end{aligned}
$$

where FM and weight are in $\mathrm{kg}$, stature in $\mathrm{cm}$, resistance and reactance in ohm.

\section{Resting energy expenditure}

REE was determined after an overnight fast by means of an open-circuit, indirect computerised calorimetry (Vmax 29; Sensor Medics, Yorba Linda, CA, USA) with a rigid, transparent, ventilated canopy. Before each test the gas analysers were calibrated using a reference gas mixture $\left(15.00 \% \mathrm{O}_{2}\right.$ and $5.00 \% \mathrm{CO}_{2}$ ). After achieving steady state in the lying position, REE of subjects was measured for $30 \mathrm{~min} . \mathrm{O}_{2}$ consumption and $\mathrm{CO}_{2}$ production, standardised for temperature, barometric pressure and humidity, were recorded at $1 \mathrm{~min}$ intervals for a minimum of $30 \mathrm{~min}$ and averaged over the whole measurement period. Results from the first 5-10 min (corresponding to adjustment to the procedural environment) and from any minutes associated with a RQ exceeding 0.95 were excluded from the analysis. Energy expenditure was derived from the measured $\mathrm{O}_{2}$ uptake and $\mathrm{CO}_{2}$ output according to the formula of de Weir (1949).

\section{Development and validation of resting energy expenditure predictive equations}

The data set of 574 measured REE (MREE) values (Group 1) was randomly split into two equal groups: a calibration group (cohort 1) for the development of predictive equations and a cross-validation group (cohort 2) for the validation of the predictive equations. In addition, the new predictive equations were validated against the data from an independent group (Group 2) of obese adolescents (Table 1). The latter was composed of fifty-three subjects (nineteen boys and thirty-four girls), aged 12-18 years, recruited from the Paediatrics Department of the Clermont-Ferrand Hospital (France), who participated in a previously published study (Lazzer et al. 2004). 
Table 1. Physical characteristics of subjects

\begin{tabular}{|c|c|c|c|c|c|c|c|c|c|c|c|c|}
\hline & \multicolumn{6}{|c|}{ Group 1† } & \multicolumn{6}{|c|}{ Group $2 \ddagger$} \\
\hline & \multicolumn{2}{|c|}{ All $(n 574)$} & \multicolumn{2}{|c|}{ Boys (n 242) } & \multicolumn{2}{|c|}{ Girls (n 332) } & \multicolumn{2}{|c|}{ All $(n 53)$} & \multicolumn{2}{|c|}{ Boys (n 19) } & \multicolumn{2}{|c|}{ Girls (n 34) } \\
\hline Age (years) & 14.53 & $2 \cdot 16$ & 14.09 & $2 \cdot 19$ & $14 \cdot 84^{\star \star \star}$ & $2 \cdot 08$ & $14 \cdot 18$ & 1.43 & $13 \cdot 70$ & 1.42 & $14 \cdot 44$ & $1 \cdot 39$ \\
\hline Pubertal stage§ & 3.85 & $1 \cdot 21$ & 3.17 & $1 \cdot 23$ & $4 \cdot 35^{\star \star \star}$ & 0.92 & 3.51 & 1.50 & 2.63 & 1.50 & $4 \cdot 00^{\star \star *}$ & $1 \cdot 28$ \\
\hline Weight $(\mathrm{kg})$ & 93.05 & 21.88 & $98 \cdot 18$ & $25 \cdot 78$ & $89 \cdot 31^{\star \star *}$ & $17 \cdot 65$ & $84 \cdot 21$ & $17 \cdot 04$ & $86 \cdot 14$ & $19 \cdot 23$ & $83 \cdot 13$ & $15 \cdot 89$ \\
\hline BMI $\left(\mathrm{kg} / \mathrm{m}^{2}\right)$ & $35 \cdot 28$ & $6 \cdot 14$ & 36.05 & $6 \cdot 64$ & $34 \cdot 71^{\star *}$ & $5 \cdot 69$ & 31.41 & 4.47 & 32.08 & 4.48 & 31.04 & 4.49 \\
\hline BMI z-score & 3.29 & 0.79 & 3.43 & 0.75 & $3 \cdot 20^{\star \star *}$ & 0.81 & 3.48 & 0.82 & 3.95 & 0.71 & $3 \cdot 22^{\star \star *}$ & 0.77 \\
\hline FFM (kg) & $48 \cdot 10$ & $10 \cdot 25$ & 50.67 & $12 \cdot 36$ & $46 \cdot 23^{\star \star \star}$ & 7.90 & 54.54 & $10 \cdot 13$ & 57.06 & $12 \cdot 86$ & $53 \cdot 12$ & $8 \cdot 12$ \\
\hline $\mathrm{FM}(\mathrm{kg})$ & 44.95 & 14.98 & 47.51 & $17 \cdot 14$ & $43 \cdot 08^{* * *}$ & 12.90 & $29 \cdot 72$ & 8.29 & $29 \cdot 15$ & 7.63 & $30 \cdot 03$ & $8 \cdot 74$ \\
\hline FM (\%) & 47.62 & $7 \cdot 32$ & 47.68 & 7.67 & 47.57 & 7.08 & 34.88 & 4.52 & 33.74 & $4 \cdot 20$ & 35.52 & 4.62 \\
\hline $\mathrm{SBP}(\mathrm{mmHg})$ & $117 \cdot 78$ & 6.49 & $119 \cdot 18$ & $6 \cdot 72$ & $116 \cdot 92^{\star \star \star}$ & $6 \cdot 21$ & 113.65 & $3 \cdot 32$ & 112.56 & 3.86 & $114 \cdot 26$ & $3 \cdot 12$ \\
\hline $\mathrm{DBP}(\mathrm{mmHg})$ & 74.07 & $6 \cdot 84$ & 73.78 & $7 \cdot 36$ & 74.25 & 6.52 & 71.69 & $2 \cdot 32$ & $70 \cdot 38$ & $2 \cdot 21$ & $72 \cdot 42$ & 2.35 \\
\hline$R Q$ & 0.85 & 0.06 & 0.85 & 0.06 & 0.84 & 0.06 & 0.84 & 0.01 & 0.84 & 0.01 & 0.84 & 0.01 \\
\hline
\end{tabular}

DBP, diastolic blood pressure; FFM, fat-free mass; FM, fat mass; REE, resting energy expenditure; SBP, systolic blood pressure.

Mean values were significantly different from those of the boys (ANOVA): ${ }^{* \star} P<0.01 ;{ }^{* \star \star} P<0.001$

† Group 1 subjects were recruited from the Division of Auxology, Italian Institute for Auxology, IRCCS, Piancavallo (VB), Italy.

$\ddagger$ Group 2 subjects were recruited from the Paediatrics Department of the Clermont-Ferrand Hospital, France.

$\S$ Pubertal stage according to Tanner (1961).

II REE adjusted for FFM and FM.

\section{Statistical analysis}

Statistical analyses were performed using Statistica for Windows (Kernel version 5.5 A; StatSoft, Maisons-Alfort, France) with significance set at $P<0.05$. All results are expressed as means and standard deviations.

In the calibration group (cohort 1), statistical analyses were performed by simple linear regression on variables related to MREE. Multivariate analyses were conducted using multiple linear regressions integrating all the significant factors in the simple linear regressions. This multivariate analysis enabled us to obtain new equations by using a stepwise selection. At each step, $R^{2}$, standard error and likelihood ratio were studied. Variables were selected if they met the $5 \%$ level of significance. These factors were introduced in a final model to predict REE.

The new prediction equations, established in the calibration group (cohort 1), were tested in the cross-validation group (cohort 2) using the Bland-Altman method to ascertain the degrees of systematic and magnitude of bias when predicted resting energy expenditure (PREE) was compared with MREE. To validate the new equations in the cross-validation group, the slope and the intercept of simple linear regression between PREE and MREE were compared with 1 and 0 , respectively.

In addition, the new predictive equations were validated against the data of the independent group of fifty-three obese adolescents (Table 1) using the Bland-Altman method to study the differences between MREE and PREE.

\section{Results}

\section{Subject characteristics}

The physical characteristics of subjects are shown in Table 1. All subjects were severely obese since BMI for gender and chronological age was above the 99th percentile.
In Group 1, with 574 subjects, BMI ranged from 25.4 to $62.0 \mathrm{~kg} / \mathrm{m}^{2}$ and BMI $z$-score ranged from 2.01 to 5.65 , age and pubertal stage were significantly lower in boys than in girls $(P<0.001)$, whereas body weight, stature, BMI and BMI $z$-score were significantly higher in boys than in girls $(+10$, $+3,+4$ and $+7 \%$, respectively, $P<0 \cdot 001$ ). Boys had higher body weight, FFM and FM, on average, than girls $(+8.87$, +4.44 and $+4.43 \mathrm{~kg}$, respectively, $P<0.001$; Table 1 ).

In the independent group (Group 2) of fifty-three subjects BMI ranged from 23.0 to $44.0 \mathrm{~kg} / \mathrm{m}^{2}$ and BMI $z$-score from 2.23 to 5.40 . Pubertal stage was significantly lower in boys than in girls $(P<0.001)$ and BMI $z$-score was significantly higher in boys than in girls $(P<0.001)$.

MREE was on average $19 \%$ higher in boys than in girls in both groups of subjects $(P<0 \cdot 001)$. After adjustment for FFM and FM in each group, the difference in REE between sexes decreased but REE remained significantly higher in boys than in girls $(+13 \%, P<0.001$; Table 1$)$.

\section{Development of new equations to predict resting energy expenditure}

The data set corresponding to the calibration group (cohort 1) was used to develop new prediction equations. The major determinants of REE were body weight and FFM. They explained $56 \%$ and $44 \%$ of the variance in simple linear regressions, respectively. Interestingly, of the remaining variables, FM exhibited the strongest relationship to REE $\left(R^{2} 0.41\right)$, followed by BMI $\left(R^{2} 0 \cdot 36\right)$, stature $\left(R^{2} 0 \cdot 32\right)$, sex $\left(R^{2} 0 \cdot 19\right)$, BMI $z$-score $\left(R^{2} 0 \cdot 14\right)$ and age $\left(R^{2} 0 \cdot 05\right)$.

In a multivariate analysis, the variables included in the equations provided a significant independent contribution to the model $(P<0.05)$. When age, weight and stature were entered in the model, $R^{2}$ was 0.66 in boys and 0.48 in girls. In addition, when sex, age, weight and stature were entered in the model $R^{2}$ was 0.66 . 
When age and the body-composition variables (FFM and FM) were entered in the model, $R^{2}$ was 0.65 in boys and 0.47 in girls. In addition, when sex, age, FFM and FM were entered in the model, $R^{2}$ was 0.66 (Table 2). The new equations based on anthropometric parameters (equation 1) or body composition (equation 2) are as follows:

$$
\begin{aligned}
& \mathrm{REE}=(\text { Sex } \times 892.68)-(\text { Age } \times 115.93)+(\text { Weight } \\
&\times 54.96)+(\text { Stature } \times 1816.23)+1484.50 ; \\
& R^{2} 0 \cdot 66(\text { SE } 1028.97) \mathrm{kJ} \\
& \mathrm{REE}=(\text { Sex } \times 909.12)-(\text { Age } \times 107.48)+(\mathrm{FFM} \\
&\times 68.39)+(\mathrm{FM} \times 55.19)+3631.23 ; \\
& R^{2} 0.66(\text { SE } 1034.28) \mathrm{kJ}
\end{aligned}
$$

where $\operatorname{sex}=1$ for males and 0 for females, REE is expressed in $\mathrm{kJ}$, age in years, weight in $\mathrm{kg}$, stature in $\mathrm{m}$, FFM and $\mathrm{FM}$ in $\mathrm{kg}$.

\section{Cross-validation of the new prediction equations}

Internal cross-validation. The data set of cohort 2 was used to validate the new equations. Mean PREE estimated with new equations 1 and 2 were not significantly different from the mean MREE (8.22 (SD 1.39) v. 8.07 (SD 1.63) MJ/d, NS) for all adolescents, as well as for boys (9.10 (SD 1.42) v. 8.88 (SD 1.87) $\mathrm{MJ} / \mathrm{d}, \mathrm{NS}$ ) and girls (7.58 (SD 0.94$)$ v. 7.48 (SD 1.11) $\mathrm{MJ} / \mathrm{d}$, NS).

The correlation coefficients between PREE and MREE were $R 0.80(P<0.001)$ for the whole sample, $R 0.81(P<0.001)$ for boys and $R 0.65 \quad(P<0.001)$ for girls. When the BlandAltman method and Student's $t$ tests were used to compare PREE and MREE, the mean difference between PREE and MREE was 0.14 (SD 0.98) $\mathrm{MJ} / \mathrm{d}$ and the limits of agreement $( \pm 2 \mathrm{SD})$ were +2.06 and $-1.77 \mathrm{MJ} / \mathrm{d}$ (NS) (Fig. 1). When a simple linear regression was applied between PREE and MREE, the slope was significantly different from 1 $(P<0.01)$ and the intercept was not significantly different from 0 .

External cross-validation. The new prediction equations were also validated against the independent group of fiftythree obese adolescents. The mean PREE estimated using equations 1 and 2 were not significantly different from MREE (7.75 (SD 1.15) and 7.78 (SD 1.16) v. 7.67 (SD 1.40) $\mathrm{MJ} / \mathrm{d}$, NS). The Bland-Altman method and Student's $t$ tests did not show any significant differences between PREE and MREE for both equations. The mean differences between PREE and MREE were 0.08 (SD 0.67) MJ/d (NS) and 0.11 (SD 0.66) $\mathrm{MJ} / \mathrm{d}$ (NS) for all adolescents, -0.06 (SD 0.70) $\mathrm{MJ} / \mathrm{d}(\mathrm{NS}$ ) and 0.01 (SD 0.71) $\mathrm{MJ} / \mathrm{d}(\mathrm{NS})$ for boys, $0 \cdot 16$ (SD 0.65 ) $\mathrm{MJ} / \mathrm{d}(\mathrm{NS})$ and 0.17 (SD 0.64) $\mathrm{MJ} / \mathrm{d}(\mathrm{NS})$ for girls, with equations 1 and 2, respectively.

\section{Discussion}

In the present study two new specific equations for predicting REE in obese children and adolescents were developed. These

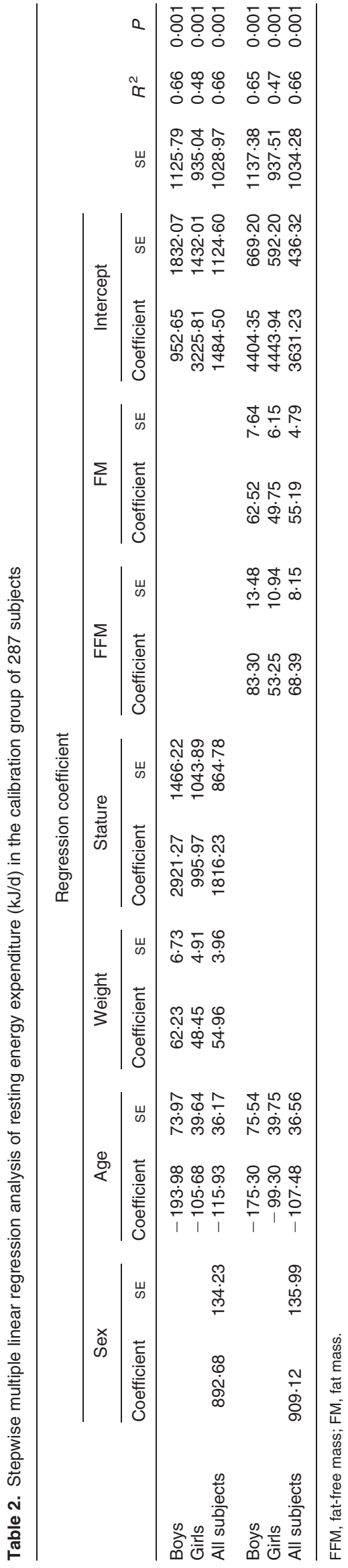


(a)

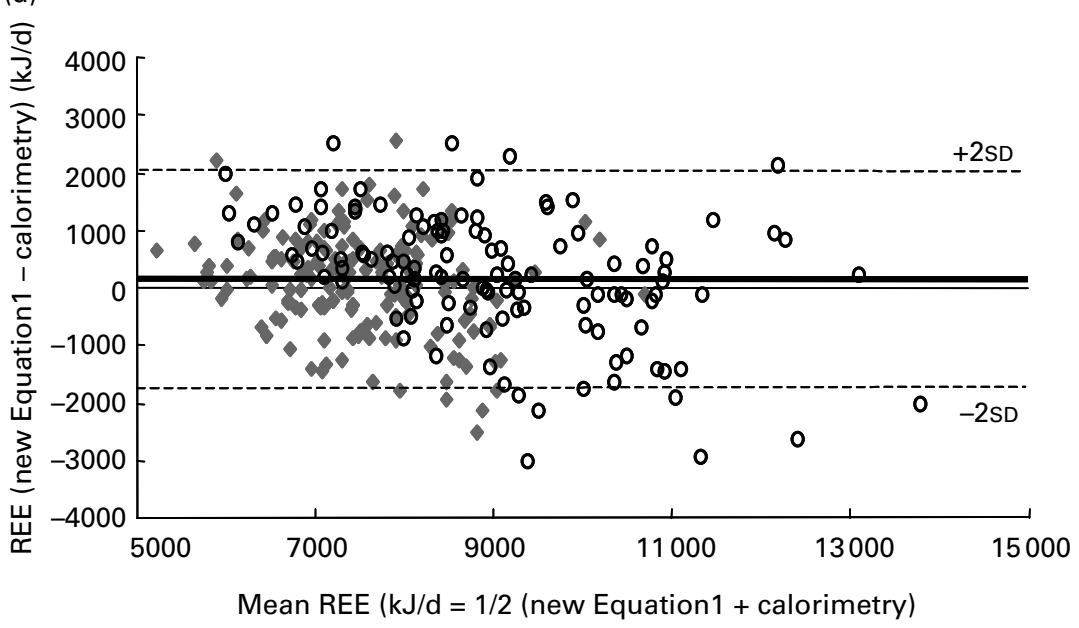

(b)

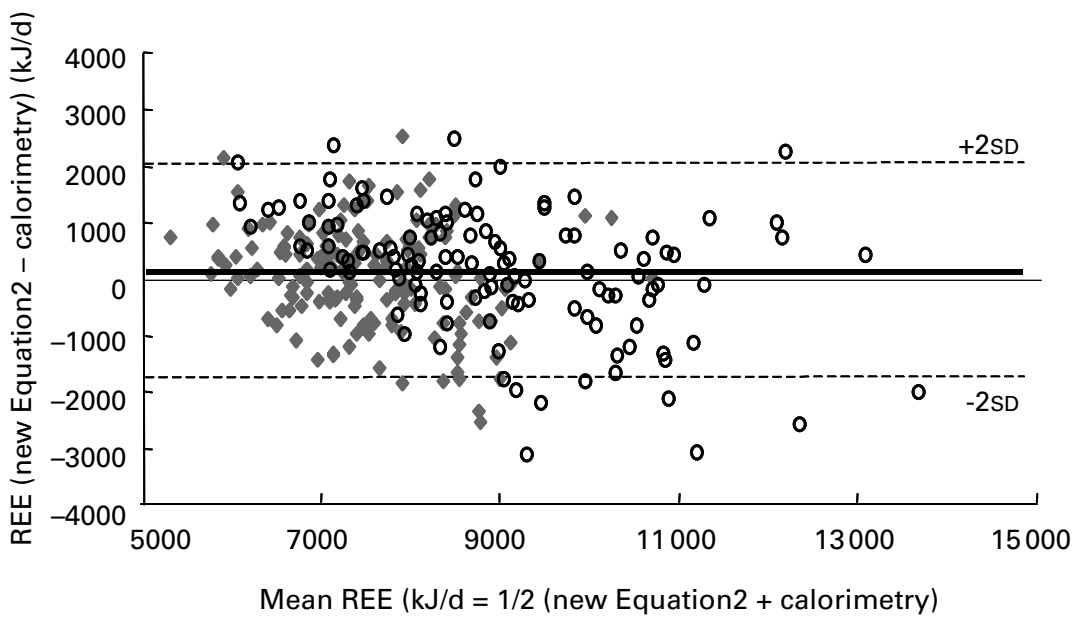

Fig. 1. The Bland-Altman representation of the difference between resting energy expenditure (REE) predicted by using the new equation 1 (a) and the new equation 2 (b) and measured REE by calorimetry in a validation cohort (compared with the Student's $t$ test). For details of procedures, see p. 974. Predictor variables for new equation 1: sex, age, weight and stature. Predictor variables for new equation 2 : sex, age, fat-free mass and fat mass. $\bigcirc$, Boys; $\bullet$, girls; - , mean, --- , limits of agreement $( \pm 2 S D)$.

equations were derived from a random sub-sample of 287 accurate measurements of REE in severely obese children and adolescents (calibration cohort), aged 7-18 years, by ventilated hood indirect calorimetry. The first prediction equation, based on anthropometric parameters (body weight and stature), is easier to use by physicians during clinical settings because it does not need extra measurement. The second equation, based on body composition (FFM and FM as assessed by BIA), is more population-specific than equation 1 because in most studies FFM and FM were the main significant determinants of REE in obese subjects (Goran et al. 1994; DeLany et al. 2002; McDuffie et al. 2004). However, it requires specific equipment and more time to assess body composition. Nevertheless, in a similar random sub-sample of 287 subjects (validation cohort), both new equations predicted REE with a mean difference of $1.9 \%$ from the MREE (NS) and did not produce any systematic bias. In addition, when an external validation was performed in an independent group of obese subjects, PREE estimated by both equations was also not significantly different from MREE. The Bland-Altman method used to validate the new equations allowed us to consider the new equations as a good tool for predicting REE in obese and in severely obese children and adolescents.

In the internal and external validation tests performed with obese children and adolescents, the two new equations showed the same small mean difference and similar standard deviation of differences between MREE and PREE even though FFM and FM have been shown to be the best predictors of REE in many studies.

Interestingly, FM showed a high correlation coefficient $\left(R^{2} 0.41\right)$ with REE, which underlines the importance of using FM also to predict REE in severely obese subjects, in agreement with previous studies (Goran et al. 1994; DeLany et al. 2002; McDuffie et al. 2004). Surprisingly in equation 2 the regression coefficients were similar for FFM and FM even though FM is known to be less metabolically active than FFM (Elia, 1992). An explanation for FM being 
involved in REE is that fat tissue secretes a component, such as leptin, in proportion to FM, which in turn increases energy expenditure. In addition, body composition was measured by BIA. BIA is a common, simple, rapid, and non-invasive method to estimate total body water and FFM in healthy people. It is also widely used for estimating body composition in obese subjects (Houtkooper et al. 1996) and it has been cross-validated in children against measurements of total body water by ${ }^{2} \mathrm{H}$ dilution (Wabitsch et al. 1996) and total body K (Schaefer et al. 1994). Some factors limit BIA application to severely obese subjects such as body geometry, body water distribution and assumption of a constant hydration factor of FFM. Reduced accuracy of BIA measurement in this population could explain the surprisingly similar predictive $R^{2}$ of the two new equations, which used body composition (FM and FFM) or stature and weight as independent variables, in contrast to previous results in normalweight or overweight subjects (Ravussin et al. 1986; DeLany et al. 2002). In addition, the relative accuracy of the BIA method is highly dependent on the equations used to calculate \%FM. Therefore, the prediction equations elaborated by Lazzer et al. (2005) and validated by dual-energy Xray absorptiometry permitted a satisfactory estimation of body composition in obese youths from measurements of stature, body weight, resistance and reactance by BIA and can reduce the methodological bias.

Sex was a significant determinant of REE and had a relevant importance in REE since after adjustment for FFM and FM, REE remained $13 \%$ higher in boys than in girls, in agreement with previous studies (Weinsier et al. 1992; Goran et al. 1994). The higher REE in boys may be explained by higher proportions of skeletal glycolytic fibres (Simoneau \& Bouchard, 1989), higher $\mathrm{Na}^{+}-\mathrm{K}^{+}$ATPase activity (Simat et al. 1983) and differences in hormonal status (Ferraro et al. 1992). In addition, the difference between genders observed in the $R^{2}$ of the new equations is probably due to the power of body weight in determining REE and the difference in body geometry and body fat distribution between boys and girls, which might limit BIA precision in girls.

In conclusion, the new prediction equations elaborated and validated in the present study permit an accurate estimation of REE in groups of severely obese children and adolescents from measurements of either anthropometric characteristics alone or body composition by BIA. These equations would be useful for health care professionals and researchers when estimating REE in severely obese adolescents.

\section{Acknowledgements}

We thank Dr M. Vermorel (INRA, France) for his valuable advice on validating the equations and improving the manuscript. We are grateful to the patients' parents and to all the children and adolescents for their co-operation, and to the head nurse and the nursing staff at the Division of Auxology, Italian Institute for Auxology, IRCCS, for their kind assistance during the study. We thank Dr J. M. H. Buckler for the language revision of the manuscript. The study was supported by Progetti di Ricerca Corrente, Italian Institute for Auxology, Milan, Italy.

\section{References}

American Diabetes Association (2000) Type 2 diabetes in children and adolescents. Diabetes Care 23, 381-389.

Bland JM \& Altman DG (1986) Statistical methods for assessing agreement between two methods of clinical measurement. Lancet 1 (8476), 307-310.

Bouchard C \& Blair SN (1999) Introductory comments for the consensus on physical activity and obesity. Med Sci Sports Exerc 31, Suppl. 11, S498-S501.

de Weir JB (1949) New methods for calculating metabolic rate with special references to protein metabolism. J Physiol (Lond) $\mathbf{1 0 9}$, $1-9$.

DeLany JP, Bray GA, Harsha DW \& Volaufova J (2002) Energy expenditure in preadolescent African American and white boys and girls: the Baton Rouge Children's Study. Am J Clin Nutr 75, $705-713$.

Derumeaux-Burel H, Meyer M, Morin L \& Boirie Y (2004) Prediction of resting energy expenditure in a large population of obese children. Am J Clin Nutr 80, 1544-1550.

Dietz WH, Bandini LG, Morelli JA, Peers KF \& Ching PL (1994) Effect of sedentary activities on resting metabolic rate. Am J Clin Nutr 59, 556-559.

Dietz WH, Bandini LG \& Schoeller DA (1991) Estimates of metabolic rate in obese and nonobese adolescents. J Pediatr 118, $146-149$.

Ekelund U, Aman J, Yngve A, Renman C, Westerterp K \& Sjostrom M (2002) Physical activity but not energy expenditure is reduced in obese adolescents: a case-control study. Am J Clin Nutr 76, 935-941.

Elia M (1992) Organ and tissue contribution to metabolic rate. In Energy Metabolism: Tissue Determinants and Cellular Corollaries, pp. 61-79 [MJ Kinney and HN Tucker, editors]. New York: Raven Press.

Ferraro R, Lillioja S, Fontvieille AM, Rising R, Bogardus C \& Ravussin E (1992) Lower sedentary metabolic rate in women compared with men. J Clin Invest 90, 780-784.

Flatt JP (2001) Macronutrient composition and food selection. Obes Res 9, Suppl. 4, 256S-262S.

Goran MI, Kaskoun M \& Johnson R (1994) Determinants of resting energy expenditure in young children. J Pediatr 125, 362-367.

Harris JA \& Benedict FG (1919) A Biometric Study of Basal Metabolism in Man. Washington, DC: Carnegie Institute of Washington.

Houtkooper LB, Lohman TG, Going SB \& Howell WH (1996) Why bioelectrical impedance analysis should be used for estimating adiposity. Am J Clin Nutr 64, Suppl. 3, 436S-448S.

Lazzer S, Boirie Y, Bitar A, Montaurier C, Vernet J, Meyer M \& Vermorel M (2003) Assessment of energy expenditure associated with physical activities in free-living obese and nonobese adolescents. Am J Clin Nutr 78, 471-479.

Lazzer S, Boirie Y, Meyer M \& Vermorel M (2005) Which alternative method to dual-energy $\mathrm{X}$-ray absorptiometry for assessing body composition in overweight and obese adolescents? Arch Pediatr 12, 1094-1101.

Lazzer S, Boirie Y, Montaurier C, Vernet J, Meyer M \& Vermorel M (2004) A weight reduction program preserves fat-free mass but not metabolic rate in obese adolescents. Obes Res 12, 233-240.

Lobstein T \& Frelut ML (2003) Prevalence of overweight among children in Europe. Obes Rev 4, 195-200.

Luciano A, Bressan F \& Zoppi G (1997) Body mass index reference curves for children aged 3-19 years from Verona, Italy. Eur J Clin Nutr 51, 6-10.

Lukaski HC (1987) Methods for the assessment of human body composition: traditional and new. Am J Clin Nutr 46, 537-556.

McDuffie JR, Adler-Wailes DC, Elberg J, Steinberg EN, Fallon EM, Tershokovec AM, Arslanian SA, Delany JP, Bray GA \& Yanovski JA (2004) Prediction equations for resting energy 
expenditure in overweight and normal-weight black and white children. Am J Clin Nutr 80, 365-373.

Maffeis C, Schutz Y, Zoccante L, Micciolo R \& Pinelli L (1993) Meal-induced thermogenesis in lean and obese prepubertal children. Am J Clin Nutr 57, 481-485.

Molnar D \& Schutz Y (1997) The effect of obesity, age, puberty and gender on resting metabolic rate in children and adolescents. Eur $J$ Pediatr 156, 376-381.

NHBP (2004) The fourth report on the diagnosis, evaluation, and treatment of high blood pressure in children and adolescents. Pediatrics 114, Suppl. 2, 555-576.

Ravussin E, Lillioja S, Anderson TE, Christin L \& Bogardus C (1986) Determinants of 24-hour energy expenditure in man. Methods and results using a respiratory chamber. J Clin Invest 78, $1568-1578$.

Rolland-Cachera MF, Cole TJ, Sempe M, Tichet J, Rossignol C \& Charraud A (1991) Body Mass Index variations: centiles from birth to 87 years. Eur J Clin Nutr 45, 13-21.

Salas-Salvado J, Barenys-Manent M, Recasens Gracia MA \& MartiHenneberg C (1993) Influence of adiposity on the thermic effect of food and exercise in lean and obese adolescents. Int J Obes Relat Metab Disord 17, 717-722.

Schaefer F, Georgi M, Zieger A \& Scharer K (1994) Usefulness of bioelectric impedance and skinfold measurements in predicting fat-free mass derived from total body potassium in children. Pediatr Res 35, 617-624.
Schofield WN (1985) Predicting basal metabolic rate, new standards and review of previous work. Hum Nutr Clin Nutr 39, Suppl. 1, $5-41$.

Simat BM, Mayrand RR, From AH, Morley JE, Billington C, Fullerton DS \& Ahmed K (1983) Is the erythrocyte sodium pump altered in human obesity? J Clin Endocrinol Metab 56, 925-929.

Simoneau JA \& Bouchard C (1989) Human variation in skeletal muscle fiber-type proportion and enzyme activities. Am J Physiol 257, E567-E572.

Tanner JM (1961) Growth at Adolescence. Oxford: Blackwell Scientific Publications.

Tverskaya R, Rising R, Brown D \& Lifshitz F (1998) Comparison of several equations and derivation of a new equation for calculating basal metabolic rate in obese children. J Am Coll Nutr 17, 333-336.

Wabitsch M, Braun U, Heinze E, Muche R, Mayer H, Teller W \& Fusch C (1996) Body composition in 5-18-y-old obese children and adolescents before and after weight reduction as assessed by deuterium dilution and bioelectrical impedance analysis. Am $J$ Clin Nutr 64, 1-6.

Weinsier RL, Schutz Y \& Bracco D (1992) Reexamination of the relationship of resting metabolic rate to fat-free mass and to the metabolically active components of fat-free mass in humans. Am J Clin Nutr 55, 790-794.

World Health Organization (1985) Energy and Protein Requirements: Report of Joint FAO/WHO/UNU Expert Consultation. WHO Technical Report Series no. 724. Geneva: WHO. 